\author{
Masaji Utsu' ${ }^{1}$ Yuichiro Kato ${ }^{1}$, Kei \\ Takehara $^{1}$ and Kazuo Maeda ${ }^{2 *}$ \\ ${ }^{1}$ Department of Obstetrics and Gynecology, Seirei \\ Mikatahara hospital, Hamamatsu, Japan \\ ${ }^{2}$ Department of Obstetrics and Gynecology, Tottori \\ University Medical School (Emeritus), Yonago, \\ Japan
}

Dates: Received: 23 June, 2016; Accepted: 11 July, 2016; Published: 12 July, 2016

*Corresponding author: Kazuo Maeda, Department of Obstetrics and Gynecology, Tottori University Medical School (Emeritus), Yonago, Japan 3-125, Nadamachi, Yonago, Tottori, 6830835, Japan, Tel: 81-859-22-6856; Fax: E-mail: maedak@mocha.ocn.ne.jp

www.peertechz.com

ISSN: 2455-3476

Keywords: Labor; Anesthesia; Vaginal submucosal injection; Pudendal nerve block; No adverse effect

\author{
Research Article
}

\section{Safe Labor Analgesia with Vaginal Submucosal Injection and Pudendal Nerve Block}

\section{Introduction}

Vaginal submucosal Injection of local anesthetic materials was one of labor pain analgesia, and the paracervical block anesthesia using Kobak needle was one of them in the past $[1,2]$, but contraindicated due to frequent reports of its side effect on the development of fetal bradycardia [3], fetal death [4] and hazardous animal experiment [5], where pudendal nerve block is still supported by some authors [6-8].

The paracervical block using Kobak needle used in past paracervical block (Figure 1) was disadvantageous because of several reasons as follows;

1. Any injection needle should be disposable and sharp, while Kobak needle was repeatedly used, in addition it was large thick and unsharp.

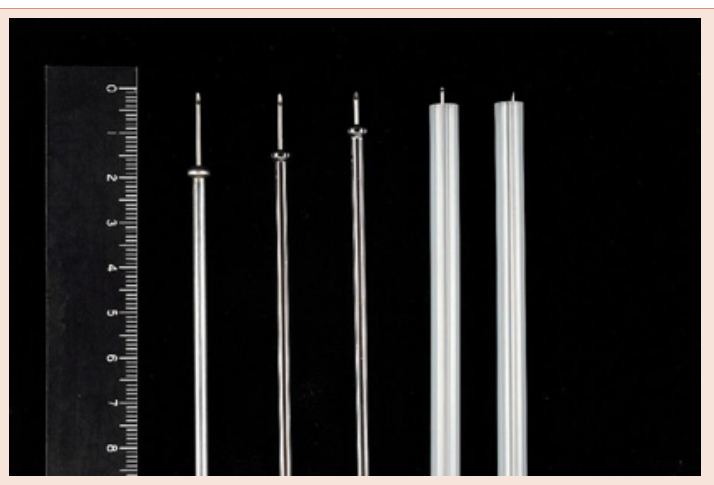

Figure 1: Three Kobak needles of 3 insertion depths $(18,14$ and $8 \mathrm{~mm})$ are shown in the left, and two disposable Cathelin needles of 5 and $2 \mathrm{~mm}$ injection depths covered by plastic sheath in current use are shown in the right.
2. Local anesthetics will stray off to uterine circulation, if the Kobak needle injected large amount of anesthetics inserting deeply for 10-15 mm, which will damage fetus developing bradycardia and/or late decelerations [9].

3. However pudendal block will be effective by $5 \mathrm{~mm}$ deep insertion, therefore Kobak needle was inserted for 10-15 mm and developed maternal pain reaching ischial bone. The Kobak needle should not be used in pudental nerve block in birth canal from these reasons.

Therefore, disposable and more fine and thin needle than Kobak one should be inserted in shallow depth. These requests are solved in the present report of safe and effective vaginal submucosal analgesia and pudental block anesthesia.

\section{Methods}

Injection needle is the disposable $22 \mathrm{G}, 14 \mathrm{~cm}$ back-cut point Cathelin injection needle covered by plastic sheath, Hakko Co. (Nagano, Japan), in the present study in 2012, after testing two needles of NIPRO and Hakko since 2005, instead of Kobak needles used in the past (Figure 1).

\section{The procedure of safe vaginal submucosal anesthesia}

The new submucosal anesthesia has been performed in the $1^{\text {st }}$ stage of labor when the external os dilatated for 5-6 cm entering into the active phase of Freedman curve.

Hakko 22G $14 \mathrm{~cm}$ long Cathelin needle covered by plastic sheath of which tip was exposed for $2 \mathrm{~mm}$ (Figure 1) was inserted into vaginal submucosal tissue, where the needle covered by plastic sheath 
was held by iodine cream covered $2^{\text {nd }}$ and $3^{\text {rd }}$ fingers of operator's left hand, and attached the tip at the 3 O'Clock point of vaginal fornix, inserting the needle tip for $2 \mathrm{~mm}$ in the tissue then $1 \%$ mepivacaine was injected for $3 \mathrm{ml}$. Then the injection was repeated at the 9 O'Clock point of right vaginal fornix, holding the needle with $2^{\text {nd }}$ and $3^{\text {rd }}$ fingers of operator's right hand (Figure 2).

\section{The procedure of safe pudendal nerve block (PNB) anesthesia}

PNB was the most effective at the full dilatation of the cervix. Hakko Co. 22G $14 \mathrm{~cm}$ long Cathelin needle was used, cutting off the tip covering sheath for $5 \mathrm{~mm}$ (Figure 1). The needle is held by iodine cream applied $2^{\text {nd }}$ and $3^{\text {rd }}$ fingers of operator's left hand, and insert the needle tip for $5 \mathrm{~mm}$ at the point immediately below the left ischial spine, then $7-10 \mathrm{ml}$ of $1 \%$ mepivacaine was injected (Figure 3). Right hand was used for the right side PNB.

\section{Results}

\section{Anesthetic effect of safe vaginal submucosal anesthesia}

The parturient woman promptly became calm immediately after safe submucosal anesthesia, laughing and speaking, due to Frankenhauser's plexus was effectively anesthetized. No change of fetal heart rate was confirmed by CTG, due to small amount injection of mepivacaine for $3 \mathrm{ml}$ into very shallow $2 \mathrm{~mm}$ deep submucosal tissue, where would be no leakage of anesthetic material into the uterine arterial blood flow.

\section{Anesthesic effect of safe PNB}

Conversation tone became calm immediately after safe PNB injection, vaginal wall tension was relaxed and softened in vaginal palpation. Neither tachypnea nor any panic situation due to pain and fear developed after the PNB.

Terminal variable deceleration of the fetus disappeared after PNB due to relaxation of vaginal wall (Figure 4). Cases of perineal incision and vaginal laceration were clearly reduced after introduction of the safe PNB.

\section{Statistics}

The total number of births was 8,121 in 8 years between April 1 of 2005 and March 31 of 2012, where 6,976 was vaginal delivery, and 4,070/6976 (58.34\%) received safe vaginal submucosal anesthesia (SVSA) and / or PNB. Single SVSA cases were 201/6976 (2.9\%) in vaginal deliveries, single PNB cases were 2,817/6976(40.4\%), and both SVSA and PNB were 1,052/6976 (15.1\%). Total SVSA cases was $1,253 / 6976$ (18.0\%) and total PNB was 1,783/6976 (25.6\%).

SVSA was repeated for 1-5 times, and total SVSA were 1,783 times. PNB cases were 3,869/6976 (55.5\%), PNB was repeated for $1-7$ times and total PNB were 5,488 times.

No anesthesia was applied in 1994-2004, where number of births was 7922, and emergency cesarean section was performed in 154 cases (1.9\%), while safe PCB and PNB anesthesia were applied in 2005-2012, where number of births was 7031 and emergency cesarean section was performed in 103 cases (1.5\%) (Table 1). There was significant reduction of emergency cesarean section rate $(\mathrm{p}=$ 0.03 in the $\chi^{2}$ test) in the period of safe PCB and PNB, while forceps operation was 299 (3.8\%) in 1994-2004 and increased to 534 (6.2\%) $(\mathrm{P}<0.001)$, passively the removal of pelvic muscle resistance in the $2^{\text {nd }}$ stage of labor would contribute smooth progress of the $2^{\text {nd }}$ stage of labor following the reduction of emergency cesarean section and increase of forceps deliveries..

\section{Discussion}

No adverse fetal bradycardia appeared in our analgesia with safe vaginal submucosal anesthesia (SVSA) and / or PNB. Although fetal bradycardia appeared in a case, it was caused by a heavy torsion of umbilical cord. A case of mild maternal anaphylactic shock recovered soon, while there was no severe maternal complication in our effective analgesia. No bacterial infection has been experienced, due to needle sterilization with iodine cream. Therefore, there was no fetal and maternal damage due to our safe labor anesthesia,

Analgesic effect was determined using the visual analgesic scale. Labor pain was reduced to 45.12 in multiparous and 55.29 in primiparous women in average, if the highest pain was 100 , the pain was reduced to about half, which will be sufficient result of analgesic procedure. Most women hoped to repeat the analgesia in the next child birth.

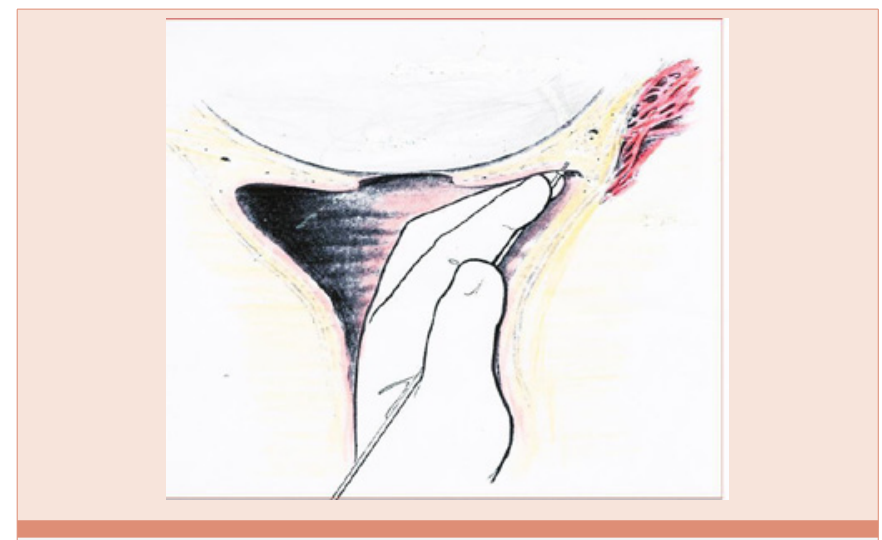

Figure 2: Vaginal technique of anesthesics injection in the safe vaginal submucosal anesthesia at the left side of patient.

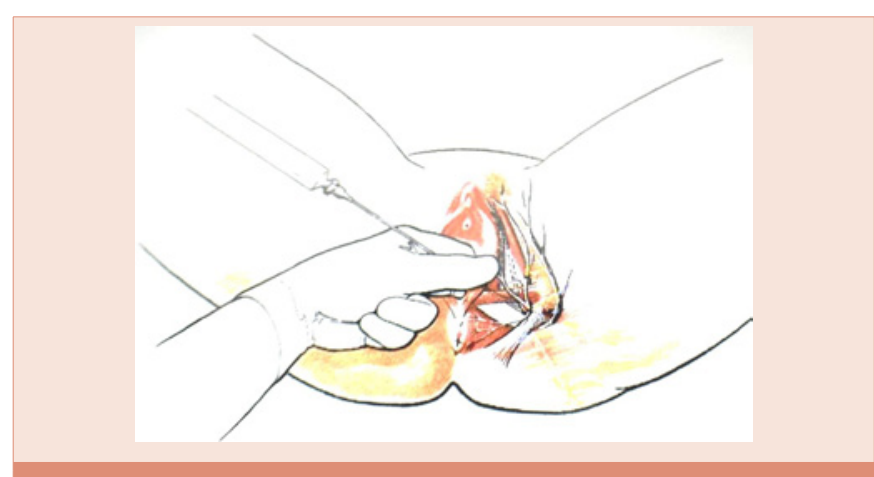

Figure 3: Safe vaginal technique of anesthetic injection in the pudendal nerve block (PNB) at the left side of patient. 


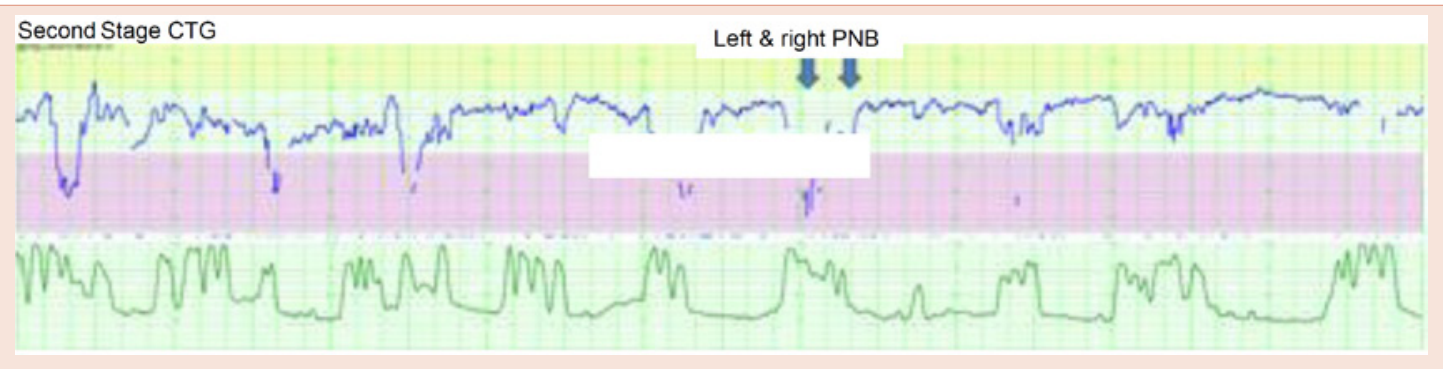

Figure 4: Variable FHR decelerations recorded in the CTG of the $2^{\text {nd }}$ stage of primiparous labor disappeared after the safe PNB (arrows at left and right sides). for each $10 \mathrm{ml}$ anesthetics, where the FHR would be improved due to reduced fetal head compression of the birth canal resistance, which was caused by the contraction of pelvic floor muscles.

Table 1: Comparison of emergency C-section due to birth arrest and NRFS in the 1994-2004 years of no anesthesia and $2005-2012$ years of safe vaginal submucosal anesthesia (SVSA) and PNB.

\begin{tabular}{|c|c|c|}
\hline Years & 1994-2004 & 2005-2012 \\
\hline Analgesia & 0 case & $\begin{array}{l}4,070 \text { SASV and / or } \\
\text { PNB cases }\end{array}$ \\
\hline No. deliveries & 7922 & 7031 \\
\hline No. emergency C-sections & 154 & 103 \\
\hline due to birth arrest and NRFS & $(1.9 \%)$ & $(1.5 \%)$ \\
\hline \multicolumn{3}{|c|}{$p=0.03$, significant reduction of emergency C-sections } \\
\hline No.forceps deivery & 299 & 534 \\
\hline $\mathrm{P}<0.001$, significant increase of vaginal delivery & $(3.8 \%)$ & $(6.2 \%)$ \\
\hline No. fetal/maternal damage in SASV and PNB & & 0 \\
\hline
\end{tabular}

Vaginal delivery would be promoted using SVSA and PNB due to the reduction of pelvic muscular resistance in the vaginal delivery, which will reduce uterine lesion and maternal morbidity due to esarean section.

Episiotomy was reduced after the introduction of SVSA and PNB, which will be the sign of perineal muscular relaxation promoting vaginal delivery.

Terminal FHR decelerations were reduced due to the relaxation of pelvic muscles and reduction of resistance to fetal head, which may reduce the cesarean section in the second stage of labor. Bloom et al [10] reported also safe paracervical block in the labor.

\section{Conclusion}

Hakko 22G Cathelin injection needle was used to achieve safe vaginal submucosal anesthesia (SVSA) and pudendal nerve block (PNB) to achieve full effective analgesia in the safe procedure with the needle insertion for $2 \mathrm{~mm}$ in SVSA and $5 \mathrm{~mm}$ in PNB in the $1^{\text {st }}$ and early $2^{\text {nd }}$ stages of labor. Vaginal delivery was promoted by the reduction of resistance of pelvic floor by the anesthetic procedure reducing cesarean sections, reducing uterine wall lesion followed by abnormal placentation in next pregnancy. Too deep needle insertion and too much injection of analgetics should be avoided, because analgesic effect is reduced and adverse effect may develop in FHR. Analgesia lasts 60-90 $\mathrm{min}$, while repeated procedure was successful. The safe SVSA and PNB were suitable anesthesia also in vaginal obstetric operations.

\section{References}

1. Kobak AJ, Evans EF, Johnson GR (1956) Transvaginal pudendal nerve block; a simple procedure for effective anesthesia in operative vaginal delivery. Am J Obstet Gynecol 71: 981-989.

2. Kobak AJ, Sadove MS (1962) Paracervical block: a transvaginal regional pain relief. Obstet Gynecol 19: 418-419.

3. Nyirjesy I, Hawks BL, Hebert JE, Hopwood HG Jr, Falls HG (1963) Hazard of the use of paracervical block anesthesia in obstetrics. Am J Obstet Gynecol 87: $231-235$

4. Baxi LV, PetrjeRH, James LS (1979) Human fetal oxygenation following paracervical block. Am J Obstet Gynecol 135: 1109-1112.

5. Morishima HO, Covino BG, Yeh MN, Stark RI, James LS (1981) Bradycardia in the fetal baboon following paracervical block anesthesia. Am J Obstet Gynecol 140: 775-780.

6. Kubota S (2004) Our contrive in the pudendal nerve block: Rinshou Fujinka Sanka (Jpan) 58: 532-535.

7. Kubota S (2000) Local anesthesia in the second stage of labor: Pudendal nerve block to achieve easy delivery. THE OSAN (Japan), Asahi Newspaper 46-49.

8. Amagase $\mathrm{H}$ (2004) Pudendal nerve block: Our contrive in pudendal nerve block. Rinsho Fujinka Sanka (Japan) 58: 536-539.

9. Amano K (1984) Paracervical block obstetrical anesthesia and fetal heart rate change. Perinatal medicine (Japan) 14: 11-15

10. Bloom SL, Horswill W, Curet LB (1972) Effects of paracervical block on the fetus during labor: A prospective study with the use of direct fetal monitoring. Am J Obstet Gynecol 114: 218-.222. 